\title{
A Baseline-Combination Method for Precise Estimation of Ice Motion in Antarctica
}

\author{
Yu Zhou, Chunxia Zhou, Dongchen E, and Zemin Wang
}

\begin{abstract}
Differential synthetic aperture radar interferometry (D-InSAR) is a powerful method for measuring surface deformation, such as in studies of the earthquake cycle, volcano deformation monitoring, land subsidence monitoring, and glaciological studies. However, its application to glaciological studies is limited by the lack of accurate digital elevation models (DEMs), particularly over the Antarctic ice sheet. Previous studies on ice motion using D-InSAR are mostly based on short-baseline interferograms because these data sets are insensitive to DEM errors. Unfortunately, short-baseline interferograms are often unavailable. In this paper, we refine the InSAR technique by using a combination of two interferograms to make accurate ice-flow velocity measurements. The refined technique is tested in the Grove Mountains area, East Antarctica. Ice-flow velocities from the baselinecombination method are in good agreement with those measured by short-baseline interferograms. This method is also capable of reducing phase errors by combining the appropriate data sets. The reliability of the data sets is assessed by defining a baselinecombination parameter and ensuring that it is less than or equal to 1.0. With this method, we are able to extend the usefulness of D-InSAR for glaciological studies.
\end{abstract}

Index Terms-Antarctic ice motion, baseline-combination method, baseline-combination parameter (bcp), differential synthetic aperture radar interferometry (D-InSAR), short baseline.

\section{INTRODUCTION}

$\mathbf{N}$ UMEROUS applications of differential synthetic aperture radar interferometry (D-InSAR) have been developed for monitoring surface deformation since Gabriel et al. [1] first measured ground displacements over agricultural fields in 1989. D-InSAR applications can be organized into several categories (e.g., land subsidence monitoring [1], studies of the earthquake cycle [2]-[9], volcano deformation monitoring [10], [11], and glaciological studies [12]-[17]). Recent advances in InSAR techniques, such as stacking [9], permanent scatterers [18], small-baseline subsets [19], and the multi-interferogram method [20], have made D-InSAR a more powerful tool for detecting subcentimeter surface deformation.

Manuscript received January 21, 2013; revised July 29, 2013; accepted November 14, 2013. Date of publication December 20, 2013; date of current version May 1, 2014. This work was supported in part by the National Nature Science Foundation of China under Grant 41076126 and Grant 41376187 and in part by the Chinese 863 program under Grant 2009AA12Z133.

Y. Zhou was with the Chinese Antarctic Center of Surveying and Mapping, Wuhan University, Wuhan 430079 , China. He is now with the Centre for the Observation and Modelling of Earthquakes, Volcanoes and Tectonics (COMET+), Department of Earth Sciences, University of Oxford, Oxford OX1 3AN, U.K.

C. Zhou, D. E, and Z. Wang are with the Chinese Antarctic Center of Surveying and Mapping, Wuhan University, Wuhan 430079, China (e-mail: zhoucx@whu.edu.cn).

Color versions of one or more of the figures in this paper are available online at http://ieeexplore.ieee.org.

Digital Object Identifier 10.1109/TGRS.2013.2292815
The capability of D-InSAR for mapping detailed ice motion has been demonstrated in many studies. Goldstein et al. [12] first measured ice motion on the Rutford Ice Stream in Antarctica. Kwok and Fahnestock [13] generated a digital elevation model (DEM) and mapped relative ice velocities in Greenland using three interferograms. Joughin et al. [14] estimated 3-D ice flow using ascending and descending passes. Rignot [15] and Rignot et al. [16], [17] measured ice motion and the position of the grounding line with InSAR data.

The use of D-InSAR for glaciological studies, particularly over the Antarctic ice sheet, is limited by several factors, such as fast ice motion and a lack of high-resolution and high-accuracy DEMs. Fast ice motion may cause decorrelation during the time interval between repeat satellite passes. However, this is unusual in Antarctic inland areas, where speeds are less than $50 \mathrm{~m} /$ year for the majority of the ice [17]. High-resolution and high-accuracy DEMs are not available for most of Antarctica. The influence of DEM errors on ice-flow measurements is proportional to the interferometric baseline length. InSAR data with short baseline lengths can reduce the DEM-introduced error, but they are often not available. Thus, the quality of the DEMs is a major problem for studies of Antarctic ice motion using traditional D-InSAR. In this paper, we refine a model from Kwok and Fahnestock [13] to eliminate the influence of inaccurate DEMs on estimation of ice motion by using a baseline-combination method. The baseline-combination method is also capable of reducing phase errors by combining appropriate baselines. We also propose a baseline-combination parameter (bcp) for constraining the combination of different perpendicular baselines.

The paper is organized as follows: In Section II, we give a brief review of D-InSAR. In Section III, traditional D-InSAR with different baseline lengths is applied to measure ice motion in the Grove Mountains area, East Antarctica, with the aim of testing the sensitivity of ice-flow measurements to DEM errors and determining whether the accuracy of the existing Antarctic DEM is suitable for ice-flow measurements. In Section IV, the baseline-combination method for the estimation of ice-flow velocity is applied. The reliability of the method is discussed in Section V, followed by conclusions in Section VI.

\section{INTERFEROMETRY REVIEW}

The theory and techniques for D-InSAR were developed and presented by Gabriel et al. [1]. This theory serves as the basis of our technique; hence, we give a brief description of D-InSAR here, in order to establish the notation used in the following sections. The geometry of repeat-pass D-InSAR is 


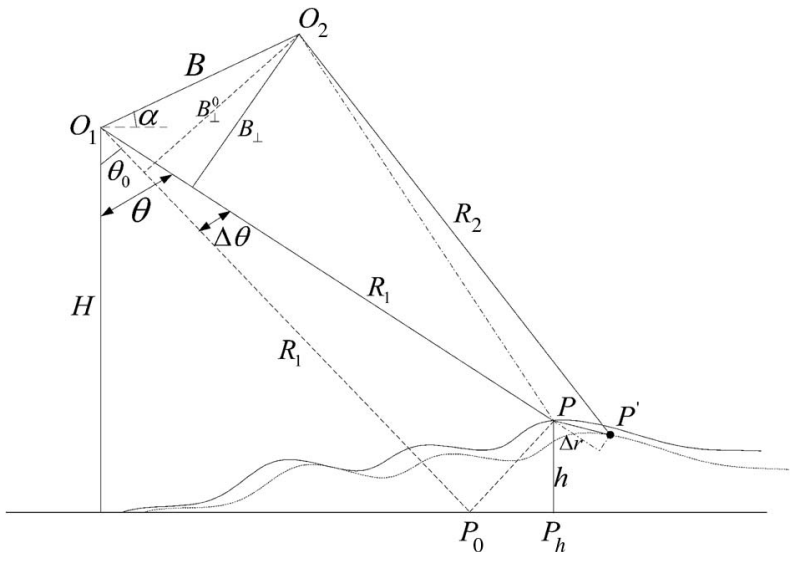

Fig. 1. Geometry of D-InSAR. The baseline $B$ can be decomposed into two directions, with one perpendicular to the line-of-sight direction (i.e., $B_{\perp}^{0}=$ $\left.B \cos \left(\theta_{0}-\alpha\right)\right)$ and the other parallel to the line-of-sight direction (i.e., $B_{\|}^{\frac{1}{0}}=$ $B \sin \left(\theta_{0}-\alpha\right)$ ), where $\theta_{0}$ is the nominal-center look angle, and $\alpha$ is the tilt of the baseline with respect to the horizontal.

shown in Fig. 1. For a repeat-pass system, two images of the same area are acquired at different times $t_{1}$ and $t_{2}$ and at different locations $\mathrm{O}_{1}$ and $\mathrm{O}_{2}$. Both SAR images are recorded as complex values $s_{1}$ and $s_{2}$, which can be expressed by amplitude $u$ and phase $\phi$. For a sample $P$, the complex values $s$ are given by

$$
\begin{aligned}
& s_{1}\left(R_{1}\right)=u_{1}\left(R_{1}\right) \exp \left(i \phi\left(R_{1}\right)\right) \\
& s_{2}\left(R_{2}\right)=u_{2}\left(R_{2}\right) \exp \left(i \phi\left(R_{2}\right)\right)
\end{aligned}
$$

where $R_{1}$ and $R_{2}$ indicate geometric distances $O_{1} P$ and $O_{2} P^{\prime}$, respectively.

After precise coregistration of the two images and resampling of $s_{2}$ to the radar geometry of $s_{1}$, a complex interferogram can be generated by complex multiplication, i.e.,

$$
s_{1}\left(R_{1}\right) s_{2}^{*}\left(R_{2}\right)=\left|s_{1} s_{2}^{*}\right| \exp i\left(\phi_{1}-\phi_{2}\right) .
$$

The observed phase values $\phi$ in the two images are calculated using the geometric distances $R_{1}$ and $R_{2}$ and the radar wavelength $\lambda$.

The interferometric phase can be written as

$$
\phi=\phi\left(R_{1}\right)-\phi\left(R_{2}\right)=-\frac{4 \pi}{\lambda}\left(R_{1}-R_{2}\right) .
$$

$\phi$ is composed of three parts, i.e., the reference phase $\phi_{\text {reference }}$ related to the reference ellipsoid, the topographic phase $\phi_{\text {topography }}$ related to the terrain, and the deformation phase $\phi_{\text {displacement }}$ related to the surface displacement. Hence

$$
\phi=\phi_{\text {reference }}+\phi_{\text {topography }}+\phi_{\text {displacement }}
$$

where

$$
\begin{aligned}
\phi_{\text {reference }} & =-\frac{4 \pi}{\lambda} \cdot B_{\|}^{0} \\
\phi_{\text {topography }} & =-\frac{4 \pi}{\lambda} \cdot \frac{B_{\perp}^{0}}{R_{1} \sin \theta_{0}} h \\
\phi_{\text {displacement }} & =-\frac{4 \pi}{\lambda} \cdot \Delta r .
\end{aligned}
$$

The surface motion along the line-of-sight direction $\Delta r$ can be determined after removing the reference phase $\phi_{\text {reference }}$ and the topographic phase $\phi_{\text {topography }}$ from the interferometric phase using an external DEM, baseline information, and other parameters such as $R_{1}, \theta_{0}$, and $\lambda$. Usually, the interferometric phase $\phi$ also contains atmospheric errors and other noise. These effects are not taken into account for the estimation of ice motion because they are difficult to quantify in Antarctica, but we will discuss the influence of these errors in Section V.

\section{Estimation OF ICE Motion}

\section{A. Study Area and Data Sets}

We acquired four pairs of Envisat SAR images with VV polarization and an incidence angle of $23.4^{\circ}$ (as detailed in Table I). The images cover the Grove Mountains area, which is located in Princess Elizabeth Land at $72^{\circ} 15^{\prime} \mathrm{S}-73^{\circ} 15^{\prime} \mathrm{S}$ and $73^{\circ} 40^{\prime} \mathrm{E}-76^{\circ} 00^{\prime} \mathrm{E}$ (see Fig. 2). The topography slopes from the southeast to the northwest with an average elevation of about $2000 \mathrm{~m}$. Based on the four InSAR pairs and using the 200-m-resolution Radarsat Antarctic Mapping Project (RAMP) DEM as the external DEM, we can test the reliability of traditional D-InSAR for estimation of Antarctic ice motion. The accuracy of the RAMP DEM [21] (shown in Table II) decreases with increasing complexity of the ice sheet surface. The perpendicular baselines of E1 and E2 are short and therefore well suited for measuring ice-flow velocities. Acquisitions E3 and E4 are not suitable for traditional D-InSAR in Antarctica because their perpendicular baselines are large.

\section{B. Ice Motion}

The D-InSAR processing method [22] for estimating ice motion is as follows. First, the single-look complexes are coregistered with subpixel accuracy. The interferogram and coherence map are estimated by multilooking in range (one look) and azimuth (five looks). Coherence is well preserved in most parts of the 35-day interferograms, which suggests that surface decorrelation due to ice motion is not a primary limiting factor for the application of D-InSAR in Antarctic inland areas. Following (5), the baseline is estimated to remove the reference phase. The topographic contribution to the interferometric phase is simulated from the RAMP DEM via (6) and then removed to calculate the contribution from motion. Before phase unwrapping, adaptive filtering for smoothing is applied. The branch-cut method is used for phase unwrapping. The ice velocity field is calculated from the resulting motion interferogram via (7) and then transformed into the groundrange direction. The velocity field is geocoded to the Universal Transverse Mercator (UTM) coordinates (as shown in Fig. 3). We select a reference point on the west side of Mount Harding (see Fig. 2) for calibrating the absolute ice velocity due to its relative stability and high coherence.

To examine the velocity estimates, we compare the results from the four InSAR pairs along two profiles shown in Fig. 3(a). The D-InSAR-derived velocities from short-baseline interferograms (the E1 and E2 data sets) are in good agreement, but the results derived from the E3 and E4 data sets are not. The error is greater with longer baselines (see Fig. 4). Errors in velocity estimates are the product of the baseline, DEM, phase 
TABLE I

ENVISAT INSAR PAIRS USED IN THIS PAPER

\begin{tabular}{|c|c|c|c|c|c|c|c|c|}
\hline \multirow{2}{*}{ ID } & \multirow{2}{*}{$\begin{array}{l}\text { Acquisition } \\
\text { dates }\end{array}$} & \multirow{2}{*}{ Track } & \multirow{2}{*}{ Frame } & \multirow{2}{*}{ Pass } & \multicolumn{2}{|c|}{ Baseline (m) } & \multirow{2}{*}{$\begin{array}{c}\text { Height } \\
\text { ambiguity }(\mathrm{m})\end{array}$} & \multirow{2}{*}{$\begin{array}{c}\text { Interval } \\
\text { (days) }\end{array}$} \\
\hline & & & & & $B_{\|}$ & $B_{\perp}$ & & \\
\hline E1 & $20060621 / 0726$ & \multirow{4}{*}{418} & \multirow{4}{*}{5139} & \multirow{4}{*}{ Descending } & -18 & -41 & 237 & \multirow{4}{*}{35} \\
\hline $\mathrm{E} 2$ & $20070606 / 0711$ & & & & 25 & -44 & 221 & \\
\hline E3 & $20060517 / 0621$ & & & & -180 & -157 & 62 & \\
\hline $\mathrm{E} 4$ & $20070502 / 0606$ & & & & -164 & 308 & -32 & \\
\hline
\end{tabular}

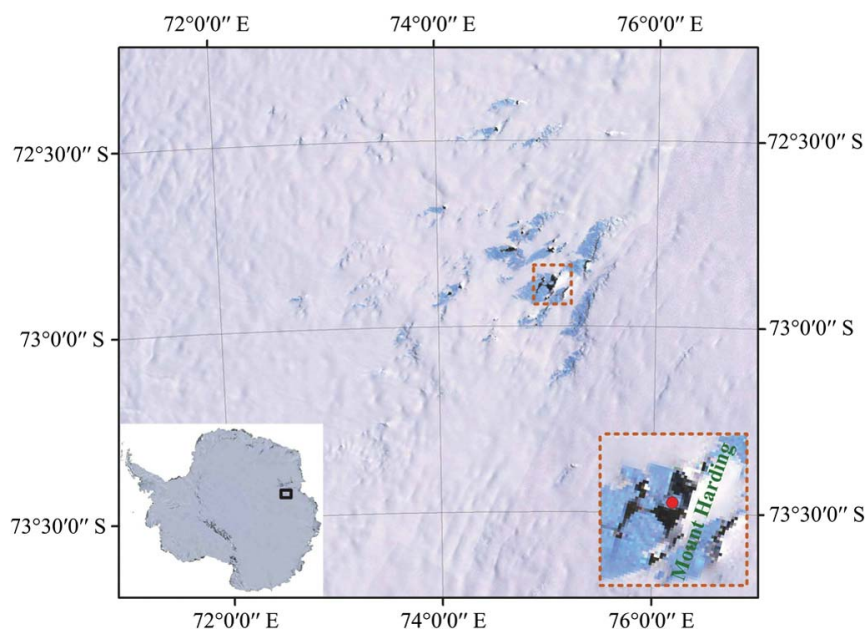

Fig. 2. Landsat image of the Grove Mountains area. A reference point (red) is selected on the west side of Mount Harding for calibrating the absolute ice motion obtained from D-InSAR, due to its relative stability and high coherence.

TABLE II

VERTICAL ACCURACY OF THE RAMP DEM [21]

\begin{tabular}{|c|l|}
\hline $\begin{array}{c}\text { Vertical } \\
\text { Accuracy }\end{array}$ & Corresponding Areas \\
\hline $\pm 1 \mathrm{~m}$ & Ice shelves \\
\hline $\pm 7.5 \mathrm{~m}$ & Gently sloping interior ice sheet \\
\hline $\pm 15 \mathrm{~m}$ & Steeply sloped coastal regions \\
\hline $\pm 17.5 \mathrm{~m}$ & $\begin{array}{l}\text { Relatively rough and steeply sloped portions of the } \\
\text { ice sheet perimeter }\end{array}$ \\
\hline $\pm 50 \mathrm{~m}$ & $\begin{array}{l}\text { Latitudes south of } 81.5^{\circ} \mathrm{S}, \text { within the interior of the } \\
\text { East Antarctic ice sheet and away from the mountain ranges }\end{array}$ \\
\hline $\pm 100 \mathrm{~m}$ & Rugged mountainous areas \\
\hline
\end{tabular}

unwrapping, and phase errors. The linear differences in our results are predominately related to the DEM errors. Referring to (6) and (7), for a perpendicular baseline of $308 \mathrm{~m}$ (e.g., the E4 pair), an elevation error of $50 \mathrm{~m}$ yields an error in velocity estimates of approximately $0.12 \mathrm{~m}$ in 35 days along the ground-range direction (i.e., $1.3 \mathrm{~m} / \mathrm{year}$ ). This error would be $2.6 \mathrm{~m} /$ year when the elevation error is $100 \mathrm{~m}$. Similarly, for a perpendicular baseline of $41 \mathrm{~m}$ (the $\mathrm{E} 1$ pair), an elevation error of $100 \mathrm{~m}$ only yields an error of $0.32 \mathrm{~m} /$ year, which can be ignored for ice-flow speeds on the order of tens of meters. Compared with the E1 pair, ice-flow velocities derived from the E2, E3, and E4 pairs have a mean difference of $0.19 \pm$ $0.34 \mathrm{~m} /$ year, $1.67 \pm 1.75 \mathrm{~m} /$ year, and $2.67 \pm 2.96 \mathrm{~m} /$ year, respectively. The difference between the four results suggests
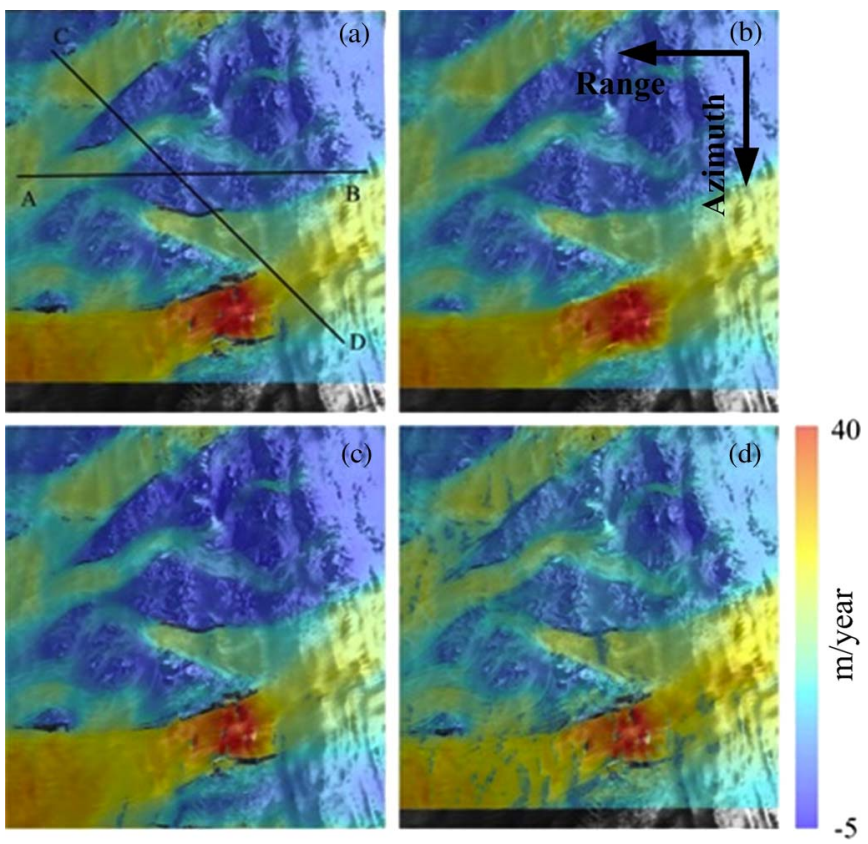

Fig. 3. Ice-flow velocities estimated from (a) E1, (b) E2, (c) E3, and (d) E4 pairs using D-InSAR (in UTM coordinates). The positive values correspond to increasing displacements in the range direction, which is the overall direction of ice motion. However, the inaccurate DEM has introduced some errors in icemotion estimates, leading to some negative velocity values on the E3 result. Profiles A-B and C-D are used to compare the four results (in Fig. 4).

that it is necessary to use short-baseline interferograms in order to lessen the influence of DEM errors, particularly in Antarctica where DEMs are relatively poor in vertical accuracy (the 30-m-resolution Advanced Spaceborne Thermal Emission and Reflection Radiometer Global DEM (ASTER GDEM) [23]) or have relatively low resolution (the 1-km-resolution Bamber DEM [24]). However, short-baseline data are often unavailable. In such cases, D-InSAR measurements cannot provide accurate information on glacier dynamics.

As a consequence, speckle tracking was proposed by Michel and Rignot [25] as a complementary means for estimation of ice motion. Speckle tracking calculates displacements in both range and azimuth directions, although, with lower resolution and poorer accuracy. In this paper, we also use the speckletracking method to estimate ice motion in the Grove Mountains area with the E1 pair (see Fig. 5). Speckle tracking is a powerful tool for mapping ice motion over large areas, e.g., entire ice sheets [17], but the low-resolution results derived from this method are inferior to D-InSAR if more detailed information is needed. Previous studies [26], [27] have suggested that measurements of ice motion derived from speckle tracking should be synthetically fused with D-InSAR measurements to achieve 

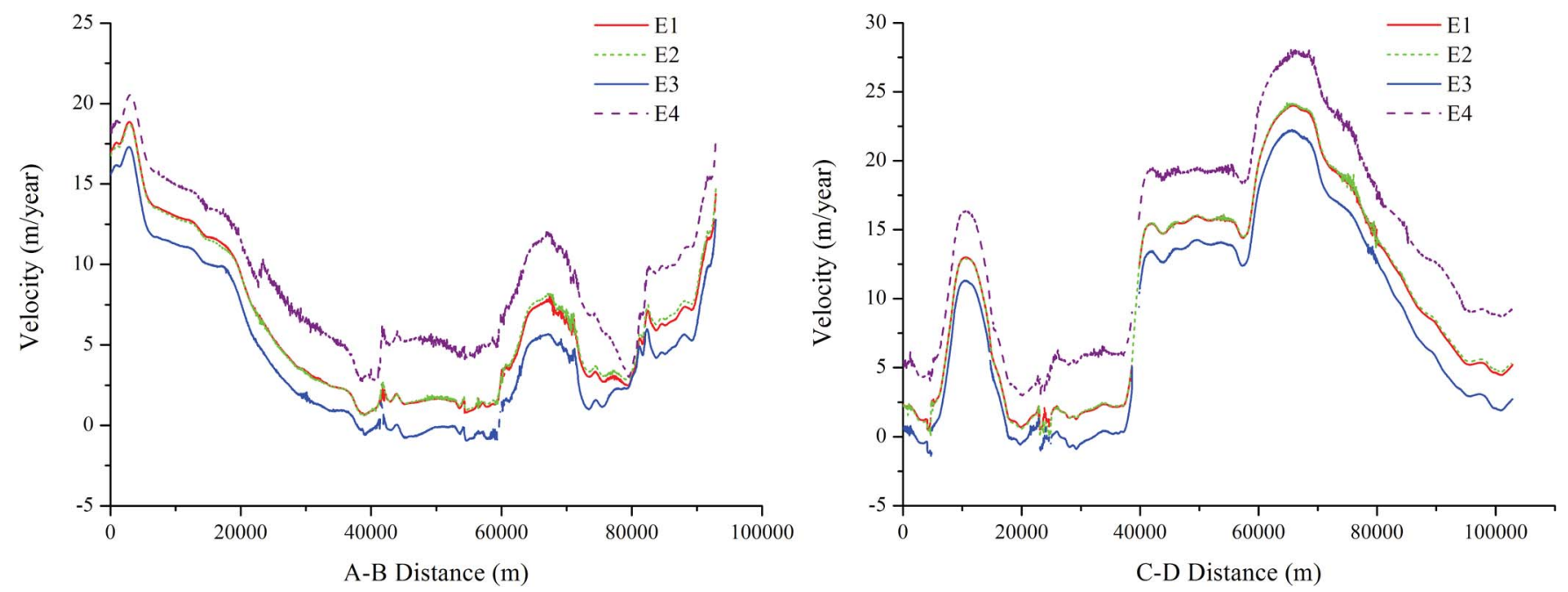

Fig. 4. Comparison of velocities obtained from the E1 (red solid line), E2 (green dotted line), E3 (blue solid line), and E4 (purple dashed line) data sets along profiles A-B and C-D. The velocity difference is greater with longer baselines. The linear differences in our results should be predominately related to DEM errors.

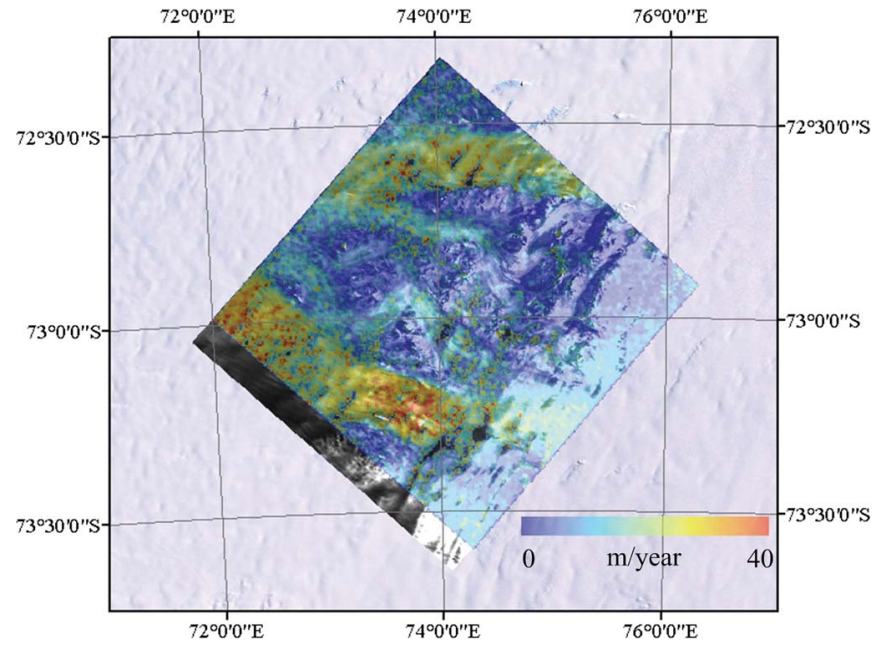

Fig. 5. Two-dimensional ice motion of the Grove Mountains area derived from the speckle-tracking method with the E1 pair. Speckle tracking is a powerful tool when mapping ice motion over large areas, but the resolution is low. Moreover, the results from speckle tracking contain large uncertainties.

better results whenever possible. Therefore, we should make accurate D-InSAR measurements over the ice sheets more widely available. In the next section, we refine the InSAR technique to eliminate the DEM-introduced errors in velocity estimates by combining two interferograms with different baseline lengths.

\section{Baseline-Combination Method For Reducing DEM-INTRODUCED ERRORS IN ICE-MOTION ESTIMATES}

\section{A. Model}

Here, we establish a baseline-combination model to reduce the DEM-introduced errors. During D-InSAR processing, we remove the reference phase $\phi_{\text {reference }}$ after applying the precise orbit determination from the Delft Institute for Earth-Oriented Space Research (DEOS), i.e.,

$$
\phi^{\prime}=\phi-\phi_{\text {reference }}
$$

where $\phi^{\prime}$ is composed of the topographic phase $\phi_{\text {topography }}$ and the deformation phase $\phi_{\text {displacement }}$. Applying (5), $\phi^{\prime}$ can be expressed as

$$
\phi^{\prime}=\phi+\frac{4 \pi}{\lambda} \cdot B_{\|}^{0}
$$

Next, we remove the topographic phase $\phi_{\text {topography }}$ using an external DEM to separate the deformation phase $\phi_{\text {displacement }}$, i.e.,

$$
\phi_{\text {displacement }}=\phi^{\prime}-\phi_{\text {topography }} .
$$

Applying (6), the deformation phase $\phi_{\text {displacement }}$ is rewritten as

$$
\phi_{\text {displacement }}=\phi^{\prime}+\frac{4 \pi}{\lambda} \cdot \frac{B_{\perp}^{0}}{R_{1} \sin \theta_{0}} h .
$$

If the surface elevation $h$ from the external DEM is highly accurate, we can obtain the deformation-only phase via (11). However, this kind of DEM is not available for most of the Antarctic ice sheet. Assuming that the surface elevation obtained from an external DEM is $h^{\prime}$ instead of $h$, then the estimated deformation phase $\phi_{\text {displacement }}^{\prime}$ obtained from D-InSAR can be expressed as

$$
\phi_{\text {displacement }}^{\prime}=\phi^{\prime}+\frac{4 \pi}{\lambda} \cdot \frac{B_{\perp}^{0}}{R_{1} \sin \theta_{0}} h^{\prime} .
$$

The difference $\Delta \phi$ between the theoretical deformation phase $\phi_{\text {displacement }}$ and the estimated deformation phase $\phi_{\text {displacement }}^{\prime}$ results from the inaccuracies of the DEM, i.e.,

$$
\Delta \phi=\phi_{\text {displacement }}^{\prime}-\phi_{\text {displacement }} .
$$

Applying (11) and (12), we can obtain

$$
\Delta \phi=\frac{4 \pi}{\lambda} \cdot \frac{B_{\perp}^{0}}{R_{1} \sin \theta_{0}}\left(h^{\prime}-h\right) .
$$

Referring to (14), the DEM-introduced errors in the ice-flow measurements are proportional to the perpendicular baseline 
length and elevation error. The theoretical deformation phase $\phi_{\text {displacement }}$ can be expressed as

$$
\phi_{\text {displacement }}=\phi_{\text {displacement }}^{\prime}+\frac{4 \pi}{\lambda} \cdot \frac{B_{\perp}^{0}}{R_{1} \sin \theta_{0}}\left(h^{\prime}-h\right) .
$$

From (15), the theoretical surface motion $\Delta r$ can be determined by

$$
\Delta r=-\frac{\lambda}{4 \pi} \cdot \phi_{\text {displacement }}^{\prime}-\frac{B_{\perp}^{0}}{R_{1} \sin \theta_{0}}\left(h^{\prime}-h\right) .
$$

Given two interferograms, applying (16), we have two equations

$$
\begin{aligned}
& v_{1} \Delta t_{1}=-\frac{\lambda}{4 \pi} \cdot \phi_{\text {displacement }, 1}^{\prime}-\frac{B_{\perp 1}^{0}}{R_{1,1} \sin \theta_{0,1}}\left(h^{\prime}-h\right) \\
& v_{2} \Delta t_{2}=-\frac{\lambda}{4 \pi} \cdot \phi_{\text {displacement }, 2}^{\prime}-\frac{B_{\perp 2}^{0}}{R_{1,2} \sin \theta_{0,2}}\left(h^{\prime}-h\right)
\end{aligned}
$$

where $v_{i}(i=1,2)$ is the ice-flow velocity along the radar lineof-sight direction, $\Delta t_{i}(i=1,2)$ is the time between acquisition of images, $\phi_{\text {displacement }, i}^{\prime}(i=1,2)$ is the estimated deformation phase by D-InSAR, $B_{\perp i}^{0}(i=1,2)$ is the perpendicular baseline, $R_{1, i}(i=1,2)$ is the geometric distance, and $\theta_{0, i}(i=$ $1,2)$ is the nominal-center look angle.

We assume that the ice-flow velocities are the same for both interferograms, i.e.,

$$
v_{1}=v_{2}=v .
$$

Combining (17)-(19), we have (20), shown at the bottom of the page.

This equation defines ice-motion estimates for the baselinecombination method. These estimates are free from the DEM errors (i.e., $\left.h^{\prime}-h\right)$. The deformation phase $\phi_{\text {displacement }, i}^{\prime}(i=$ $1,2)$ must be derived using the same external DEM to keep the DEM-introduced errors equal.

\section{B. Experiments and Results}

An implicit assumption in the derivation of (20) is that the ice-flow velocities are constant for the different interferograms. This assumption is reasonable if SAR images are all obtained in the same season. The data sets we used in this paper were acquired between May and July. We believe there is very slight velocity change during this period. The coincident iceflow velocities estimated by the E1 and E2 pairs support the steady ice-flow assumption over the Grove Mountains area. Thus, we carry out our experiment using the E3 and E4 InSAR pairs referring to (20), after estimating the deformation phase $\phi_{\text {displacement }, i}^{\prime}(i=1,2)$, by removing the topographic phase using the RAMP DEM. The ice-flow velocity map estimated by (20) is shown in Fig. 6. The ice velocities from the baselinecombination method are in good agreement with the results

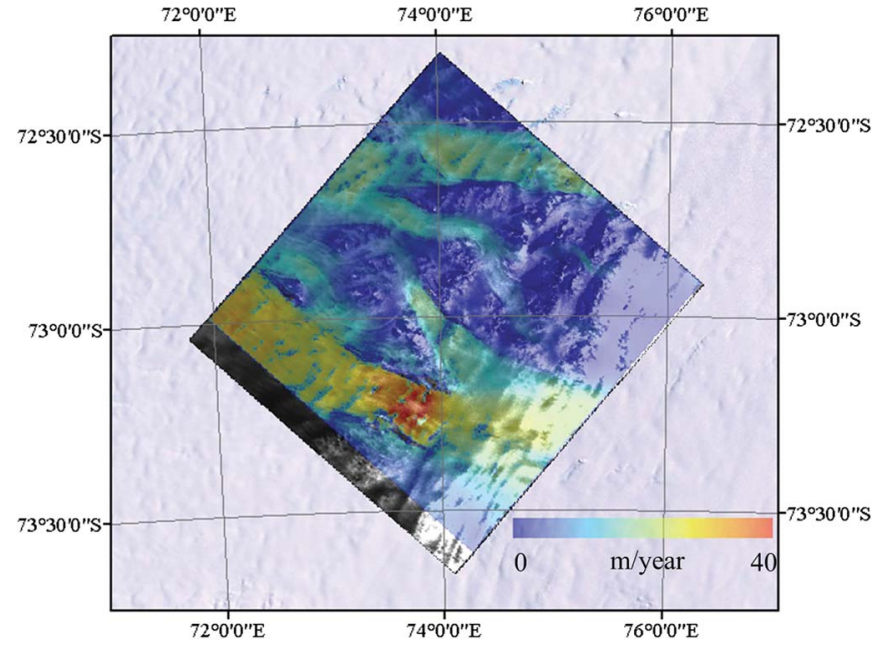

Fig. 6. Ice-flow velocity map estimated by the baseline-combination method. from the E1 and E2 data, which are short-baseline interferograms (see Fig. 7). The differences between these results are less than $0.4 \mathrm{~m} /$ year for most areas, with several values reaching up to $0.7 \mathrm{~m} / \mathrm{year}$. We discuss the errors associated with the baseline-combination method and constraints on its application in the next section.

\section{DISCUSSION}

We measured ice-flow velocities in the Grove Mountains area using both the traditional D-InSAR and the baselinecombination method. The coincident results indicate that it is feasible to precisely measure ice motion without a good DEM using a combination of long-baseline interferograms. In the baseline-combination technique, selection of the baselines is the major issue as different combinations have a different influence on error propagation. Although we do not need to consider topographic errors for this method, other errors including misregistration, baseline, phase unwrapping and phase errors will still occur. Here, we discuss the baseline-combination strategy based on error analysis.

Misregistration errors are often introduced when interferograms are not precisely coregistered. Our data were coregistered with good accuracy, so misregistration errors are not discussed. Baseline and phase errors (mainly atmospheric delays) are often the primary error sources when estimating the deformation phase $\phi_{\text {displacement }}^{\prime}$. For simplicity, we suppose the time intervals are equal (i.e., $\Delta t_{i}=\Delta t(i=1,2)$ ) and use the Envisat satellite parameters in (20). Applying the error propagation law, the ice-flow velocity error $\delta_{v}$ is written as (21), shown at the bottom of the next page, where $\delta_{\phi_{i}^{\prime}}(i=1,2)$ is the error of the estimated deformation phase $\phi_{\text {displacement }}^{\prime}$, which is mainly introduced by atmospheric delays; $\delta_{B_{\perp i}^{0}}^{2}(i=1,2)$ is the error of the perpendicular baseline; and $\left(\phi_{1}^{\prime}-\phi_{2}^{\prime}\right)$ is the phase difference that is caused by different phase errors.

$$
v=-\frac{\lambda}{4 \pi} \cdot \frac{\frac{B_{\perp 2}^{0}}{R_{1,2} \sin \theta_{0,2}} \cdot \phi_{\text {displacement }, 1}^{\prime}-\frac{B_{\perp 1}^{0}}{R_{1,1} \sin \theta_{0,1}} \cdot \phi_{\text {displacement }, 2}^{\prime}}{\frac{B_{\perp 2}^{0}}{R_{1,2} \sin \theta_{0,2}} \cdot \Delta t_{1}-\frac{B_{\perp 1}^{0}}{R_{1,1} \sin \theta_{0,1}} \cdot \Delta t_{2}}
$$



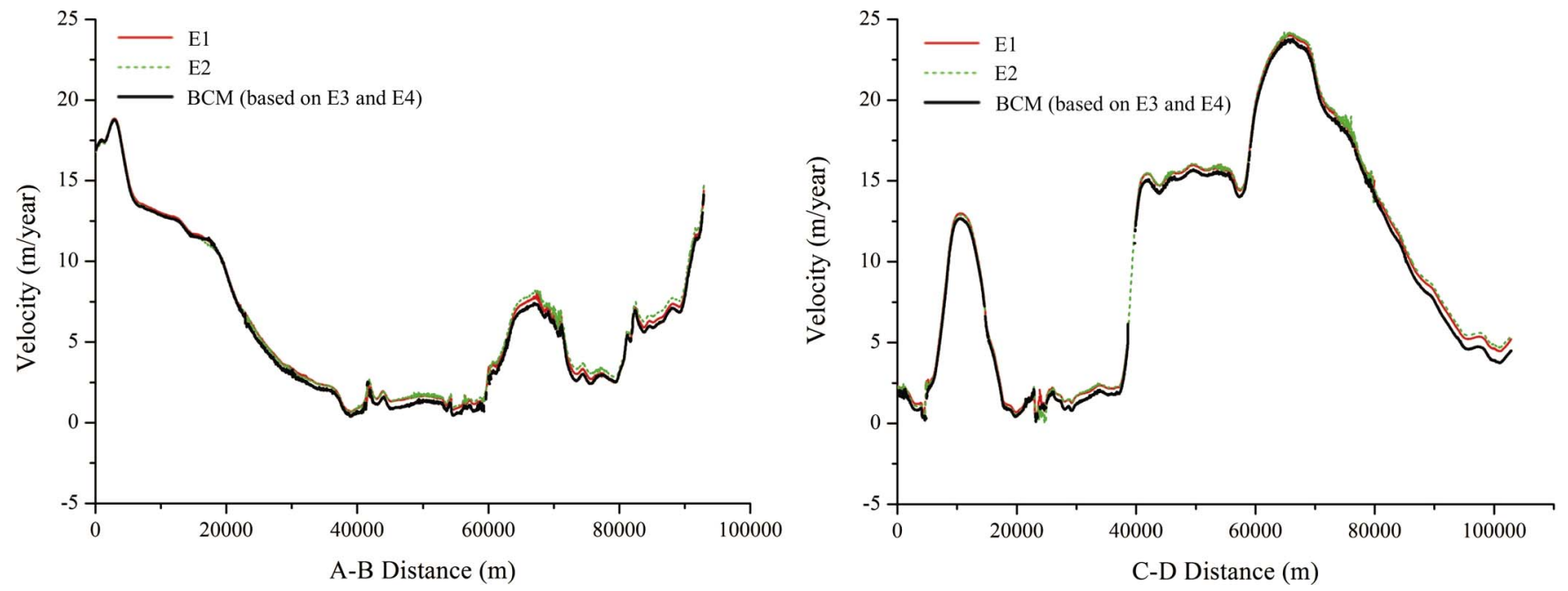

Fig. 7. Comparison of velocities obtained from the E1 (red solid line), E2 (green dotted line), and baseline-combination method (BCM, black solid line) along profiles A-B and C-D. The ice velocities from the baseline-combination method are in good agreement with the results from the E1 and E2 pairs with short baseline lengths. The differences between these results are less than $0.4 \mathrm{~m} / \mathrm{year}$ for most areas, with several values reaching up to $0.7 \mathrm{~m} / \mathrm{year}$.

To further simplify $\delta_{v}$, we assume that atmospheric delays are uniform (i.e., $\delta_{\phi_{i}^{\prime}}=\delta_{\phi}(i=1,2)$ ), and the phase difference $\left(\phi_{1}^{\prime}-\phi_{2}^{\prime}\right)$ is $\pm 2 \delta_{\phi}$. For Envisat, the orbital error after using the precise orbit determination is estimated to be $3 \mathrm{~cm}$ in the radial component and $10 \mathrm{~cm}$ in 3-D [28]. The influence of the perpendicular baseline errors (i.e., $\left(B_{\perp 2}^{0} \cdot\left(\phi_{1}^{\prime}-\phi_{2}^{\prime}\right) /\left(B_{\perp 2}^{0}-\right.\right.$ $\left.\left.\left.B_{\perp 1}^{0}\right)^{2}\right)^{2} \cdot \delta_{B_{\perp 1}^{0}}^{2}+\left(B_{\perp 1}^{0} \cdot\left(\phi_{1}^{\prime}-\phi_{2}^{\prime}\right) /\left(B_{\perp 2}^{0}-B_{\perp 1}^{0}\right)^{2}\right)^{2} \cdot \delta_{B_{\perp 2}^{0}}^{2}\right)$ is insignificant compared to the atmospheric delays, since the ratio of $\left(B_{\perp 2}^{0} \cdot\left(\phi_{1}^{\prime}-\phi_{2}^{\prime}\right) /\left(B_{\perp 2}^{0}-B_{\perp 1}^{0}\right)^{2}\right)^{2} \cdot \delta_{B_{\perp 1}^{0}}^{2}$ to $\left(B_{\perp 2}^{0} /\right.$ $\left(B_{\perp 2}^{0}-B_{\perp 1}^{0}\right)^{2} \cdot \delta_{\phi_{1}^{\prime}}^{2}$ is $4 \delta_{B_{\perp 1}^{0}}^{2} /\left(B_{\perp 2}^{0}-B_{\perp 1}^{0}\right)^{2}$, which is normally on the order of $10^{-3}$ to $10^{-6}$ (depending on the baseline difference). Thus, $\delta_{v}$ can be simply written as

$$
\begin{aligned}
\delta_{v} & \approx \frac{\lambda}{4 \pi \cdot \Delta t} \cdot \sqrt{\left(\frac{B_{\perp 2}^{0}}{B_{\perp 2}^{0}-B_{\perp 1}^{0}}\right)^{2} \cdot \delta_{\phi_{1}^{\prime}}^{2}+\left(\frac{B_{\perp 1}^{0}}{B_{\perp 2}^{0}-B_{\perp 1}^{0}}\right)^{2} \cdot \delta_{\phi_{2}^{\prime}}^{2}} \\
& =\frac{\lambda \cdot \delta_{\phi}}{4 \pi \cdot \Delta t} \cdot \sqrt{\left(\frac{B_{\perp 2}^{0}}{B_{\perp 2}^{0}-B_{\perp 1}^{0}}\right)^{2}+\left(\frac{B_{\perp 1}^{0}}{B_{\perp 2}^{0}-B_{\perp 1}^{0}}\right)^{2}}
\end{aligned}
$$

In the baseline-combination method, $\delta_{v}$ largely depends on the baseline combinations. We propose a baseline-combination parameter $(b c p)$ to verify the reliability of this method, i.e.,

$$
b c p=\left(\frac{B_{\perp 2}^{0}}{B_{\perp 2}^{0}-B_{\perp 1}^{0}}\right)^{2}+\left(\frac{B_{\perp 1}^{0}}{B_{\perp 2}^{0}-B_{\perp 1}^{0}}\right)^{2} .
$$

Fig. 8 shows the value of the $b c p$ for different baseline combinations. Perpendicular baselines larger than $400 \mathrm{~m}$ are not suggested because they may cause decorrelation. The baselinecombination method is more accurate for lower $b c p$ s. According to (22), if the $b c p>1$, phase errors will be magnified when

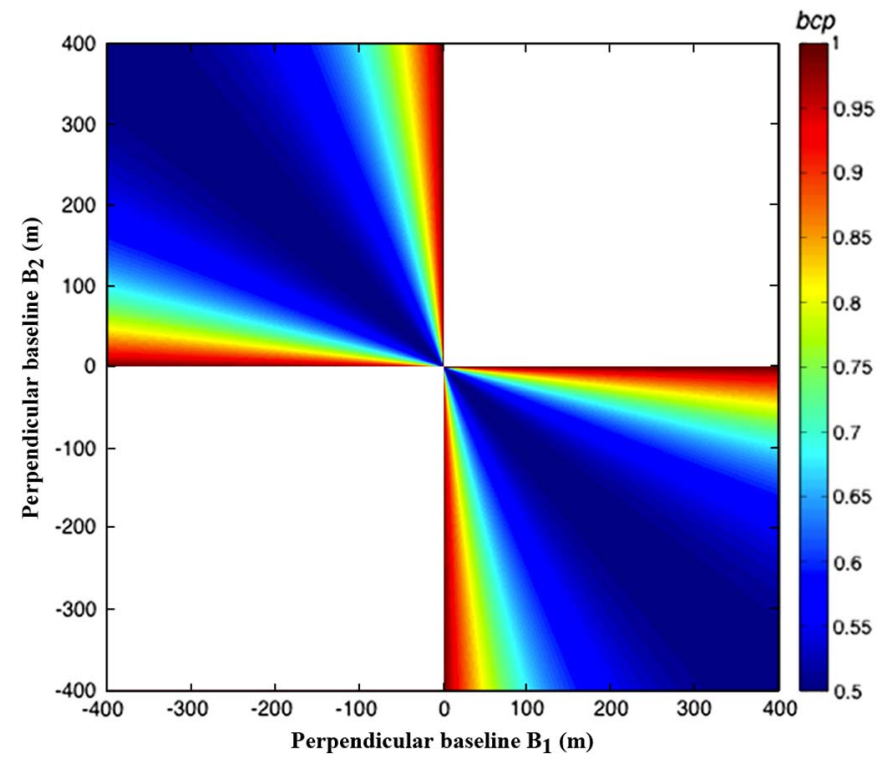

Fig. 8. bcp space. We do not suggest using interferograms with a perpendicular baseline of over $400 \mathrm{~m}$ because of decorrelation. We also constrain $0.5 \leq b c p \leq 1.0$; thus, combinations with a $b c p$ of larger than 1.0 are null (white area). The baseline-combination method is more accurate for lower bcps.

using the baseline-combination method to estimate ice motion. We constrain $0.5 \leq b c p \leq 1.0$ for the method, which means that baseline combinations with a $b c p$ of over 1.0 should not be used. The $b c p$ of the E3 and E4 combination is $\sim 0.55$, suggesting that the phase errors can be reduced by $\sim 0.26$. The differences between the baseline-combination and short-baseline results are because our method and data sets are capable of reducing the DEM and some of the phase errors. For the E1 and E2 combination, the $b c p$ is extremely large, varying from

$$
\delta_{v}=\frac{\lambda}{4 \pi \cdot \Delta t} \cdot \sqrt{\left(\frac{B_{\perp 2}^{0}}{B_{\perp 2}^{0}-B_{\perp 1}^{0}}\right)^{2} \cdot \delta_{\phi_{1}^{\prime}}^{2}+\left(\frac{B_{\perp 1}^{0}}{B_{\perp 2}^{0}-B_{\perp 1}^{0}}\right)^{2} \cdot \delta_{\phi_{2}^{\prime}}^{2}+\left(\frac{B_{\perp 2}^{0} \cdot\left(\phi_{1}^{\prime}-\phi_{2}^{\prime}\right)}{\left(B_{\perp 2}^{0}-B_{\perp 1}^{0}\right)^{2}}\right)^{2} \cdot \delta_{B_{\perp 1}^{0}}^{2}+\left(\frac{B_{\perp 1}^{0} \cdot\left(\phi_{1}^{\prime}-\phi_{2}^{\prime}\right)}{\left(B_{\perp 2}^{0}-B_{\perp 1}^{0}\right)^{2}} \cdot \delta_{B_{\perp 2}^{0}}^{2}\right.}
$$



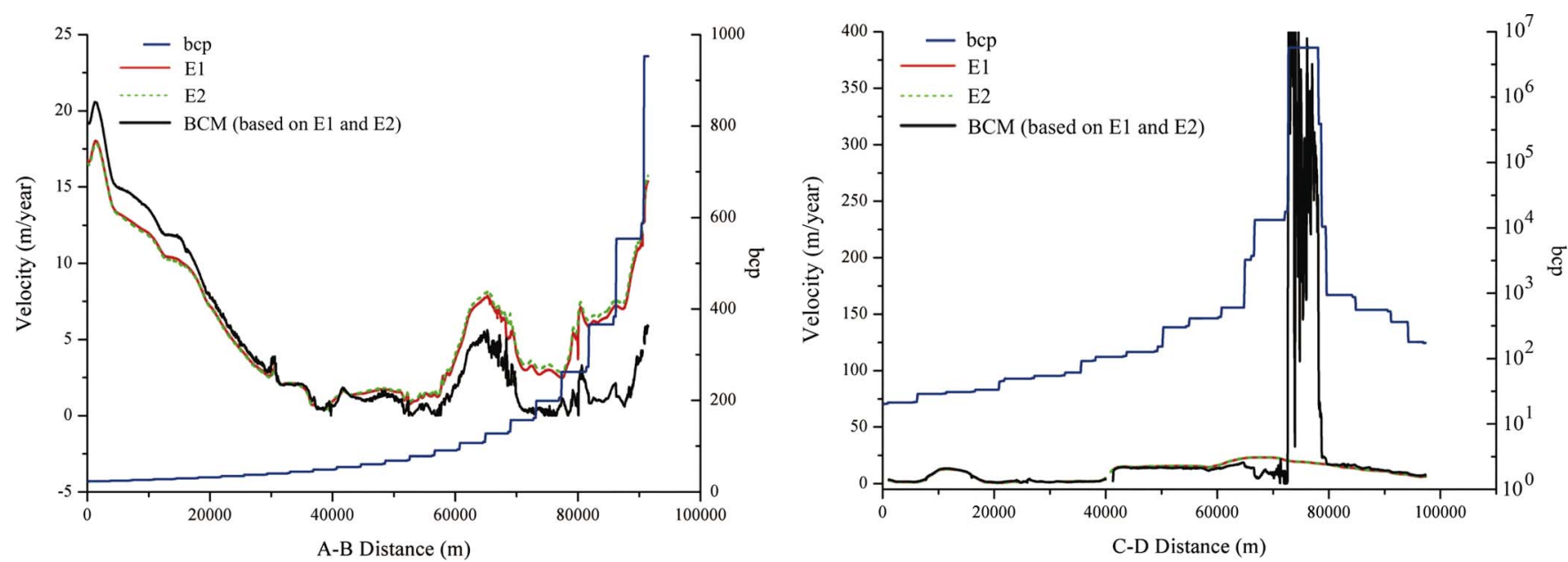

Fig. 9. Ice-flow velocity and $b c p$ profiles for the $\mathrm{E} 1$ and $\mathrm{E} 2$ combination. The error of the baseline-combination ice velocity largely depends on the $b c p$. The error reaches up to $\sim 350 \mathrm{~m} /$ year when $b c p \approx 10^{7}$. Along profile A-B, the velocity variations at $0-20 \mathrm{~km}$ are much larger than the $20-40 \mathrm{~km}$ region, where $b c p$ is much bigger, as the atmospheric delays can be more significant in this segment. The atmospheric delays vary considerably with space, which can also be clearly seen on profile C-D, where the bcp is over $10^{4}$.

1 to $10^{7}$. As a test, we use E1 and E2 to measure the iceflow velocity field via (20). Although the perpendicular baseline length of E1 and E2 is relatively short, the baseline-combination result is much worse than the result from combining E3 and E4 (as shown in Fig. 9). The error strongly correlates with the $b c p$, e.g., for $b c p \approx 10^{7}$, the error can be $\sim 350 \mathrm{~m} /$ year. The significant difference between the baseline-combination and short-baseline results confirms that large bcps should be avoided in the baseline-combination method.

For the traditional D-InSAR approach, the ice-flow velocity error $\delta_{v}^{\prime}$ is given by

$\delta_{v}^{\prime}=\frac{1}{\Delta t} \sqrt{\left(\frac{\lambda}{4 \pi}\right)^{2} \delta_{\phi}^{2}+\left(\frac{B_{\perp}^{0}}{R_{1} \sin \theta_{0}}\right)^{2} \delta_{h}^{2}+\left(\frac{h}{R_{1} \sin \theta_{0}}\right)^{2} \delta_{B_{\perp}^{0}}^{2}}$

where $\delta_{h}$ is the elevation error.

Similarly, the influence of the perpendicular baseline error can be neglected, as the ratio of $\left(h / R_{1} \sin \theta_{0}\right)^{2} \delta_{B_{\perp}^{0}}^{2}$ to $\left(B_{\perp}^{0} / R_{1} \sin \theta_{0}\right)^{2} \delta_{h}^{2}$ is small. Thus we can get

$$
\delta_{v}^{\prime} \approx \frac{1}{\Delta t} \sqrt{\left(\frac{\lambda}{4 \pi}\right)^{2} \delta_{\phi}^{2}+\left(\frac{B_{\perp}^{0}}{R_{1} \sin \theta_{0}}\right)^{2} \delta_{h}^{2}} .
$$

Theoretically, the error in velocity estimates from traditional D-InSAR (even using short-baseline interferograms) can be larger than the baseline-combination method (for $0.5 \leq b c p \leq 1.0$ ). As a result, we suggest that the baseline-combination method should be the preferred method for estimation of ice motion.

\section{CONCLUSiON}

Ice-flow velocity is a crucial parameter in dynamic models of the Antarctic ice sheet, which indicates how ice is transported from the interior to the ocean and how ice mass evolves [17]. Ice motion is relatively slow in Antarctic inland areas, where D-InSAR is able to provide detailed and accurate measurements of ice motion, particularly when both ascending and descending passes can be obtained to estimate the three-component velocity vector. The $3-\mathrm{D}$ velocity estimation is based on accurate
D-InSAR measurements, and this requires the accurate removal of the topographic phase from the interferometric phase. Such requirements cannot always be satisfied over the Antarctic ice sheet, where accurate DEMs and short-baseline interferograms are often unavailable. Consequently, the application of traditional D-InSAR in glaciological studies has been limited.

The influence of the DEM errors must be eliminated in order to widen the use of traditional D-InSAR within Antarctic glaciology. In this paper, we build such a model by refining the method proposed by Kwok and Fahnestock [13]. The baselinecombination method is tested in the Grove Mountains area. The baseline-combination result is in good agreement with the measurements from the short-baseline interferograms. Accurate ice-motion estimates without short-baseline interferograms and good DEMs are feasible if ice-flow velocities remain constant for different interferograms. Our study suggests that the assumption of steady ice-flow velocities in Antarctic inland areas is reasonable.

Considering other error sources (e.g., the baseline and phase errors), we propose the $b c p$ to verify the reliability of the baseline-combination method. When the bcp is low, the baseline-combination method is able to reduce some phase errors, which suggests that this method is better than traditional D-InSAR for large atmospheric delays.

Using the baseline-combination method, we extend the usefulness of D-InSAR for glaciological studies. Based on this method, it is possible to map more detailed and accurate iceflow velocities with a synthetic fusion of D-InSAR and speckle tracking, or from using ascending and descending passes from existing and future missions, such as the Sentinel series.

\section{ACKNOWLEDGMENT}

The authors would like to thank the European Space Agency through the International Polar Year announcement of opportunity (ID 1685) for providing the SAR data, the National Snow and Ice Data Center for the RAMP DEM, the Landsat Image Mosaic of Antarctica for the Landsat images, and two anonymous reviewers for their constructive comments and suggestions. 


\section{REFERENCES}

[1] A. K. Gabriel, R. M. Goldstein, and H. A. Zebker, "Mapping small elevation changes over large areas: Differential radar interferometry," J. Geophys. Res., vol. 94, no. B7, pp. 9183-9191, Jul. 1989.

[2] J. R. Elliot, A. C. Copley, R. Holley, K. Scharer, and B. Parsons, "The 2011 Mw 7.1 Van (Eastern Turkey) earthquake," J. Geophys. Res., vol. 118, no. 4, pp. 1619-1637, Apr. 2013.

[3] D. Massonnet, K. Feigl, M. Rossi, and F. Adragna, "Radar interferometric mapping of deformation in the year after the Landers earthquake," Nature, vol. 369, no. 6477, pp. 227-230, May 1994.

[4] J. R. Elliott, J. Biggs, B. Parsons, and T. J. Wright, "InSAR slip rate determination on the Altyn Tagh Fault, northern Tibet, in the presence of topographically correlated atmospheric delays," Geophys. Res. Lett., vol. 35, no. 12, pp. L12309-1-L12309-5, Jun. 2008.

[5] J. R. Elliott, E. K. Nissen, P. C. England, J. A. Jackson, S. Lamb, Z. Li, M. Oehlers, and B. Parsons, "Slip in the 2010-2011 Canterbury earthquakes, New Zealand," J. Geophys. Res., vol. 117, no. B3, pp. B03401-1B03401-36, Mar. 2012.

[6] F. F. Pollitz, C. Wicks, and W. Thatcher, "Mantle flow beneath a continental strike-slip fault: Postseismic deformation after the 1999 Hector mine earthquake," Science, vol. 293, no. 5536, pp. 1814-1818, Sep. 2001.

[7] I. Ryder, B. Parsons, T. J. Wright, and G. J. Funning, "Post-seismic motion following the 1997 Manyi (Tibet) earthquake: InSAR observations and modelling," Geophys. J. Int., vol. 169, no. 3, pp. 1009-1027, Jun. 2007

[8] M. A. Bell, J. R. Elliott, and B. E. Parsons, "Interseismic strain accumulation across the Manyi Fault (Tibet) prior to the $1997 \mathrm{Mw} 7.6$ earthquake," Geophys. Res. Lett., vol. 38, no. 24, pp. L24302-1-L24302-6, Dec. 2011.

[9] T. Wright, B. Parsons, and E. Fielding, "Measurement of interseismic strain accumulation across the North Anatolian Fault by satellite radar interferometry," Geophys. Res. Lett., vol. 28, no. 10, pp. 2117-2120, May 2001

[10] M. Parks, J. Biggs, P. England, T. Mather, P. Nomikou, K. Palamartchouk, X. Papanikolaou, D. Paradissis, B. Parsons, D. Pyle, C. Raptakis, and V. Zacharis, "Evolution of Santorini Volcano dominated by episodic and rapid fluxes of melt from depth," Nat. Geosci., vol. 5, no. 19, pp. 749-754, Oct. 2012.

[11] S. K. Ebmeier, J. Biggs, T. A. Mather, J. R. Elliott, G. Wadge, and F. Amelung, "Measuring large topographic change with InSAR: Lava thicknesses, extrusion rate and subsidence rate at Santiaguito volcano, Guatemala," Earth Planet. Sci. Lett., vol. 335/336, pp. 216-225, Jun. 2012.

[12] R. M. Goldstein, H. Engelhardt, B. Kamb, and R. M. Frolich, "Satellite radar interferometry for monitoring ice sheet motion: Application to an Antarctic ice stream," Science, vol. 262, no. 5139, pp. 1525-1530, Dec. 1993.

[13] R. Kwok and M. A. Fahnestock, "Ice sheet motion and topography from radar interferometry," IEEE Trans. Geosci. Remote Sens., vol. 34, no. 1, pp. 189-200, Jan. 1996.

[14] I. R. Joughin, R. Kwok, and M. A. Fahnestock, "Interferometric estimation of three-dimensional ice-flow using ascending and descending passes," IEEE Trans. Geosci. Remote Sens., vol. 36, no. 1, pp. 25-37, Jan. 1998

[15] E. Rignot, "Tidal flexure, ice velocities and ablation rates of Petermann Gletscher, Greenland," J. Glaciol., vol. 42, no. 142, pp. 476-485, Mar. 1996.

[16] E. Rignot, J. Mouginot, and B. Scheuchl, "Antarctic grounding line mapping from differential satellite radar interferometry," Geophys. Res. Lett., vol. 38, no. 10, pp. L10504-1-L10504-6, May 2011.

[17] E. Rignot, J. Mouginot, and B. Scheuchl, "Ice flow of the Antarctic ice sheet," Science, vol. 333, no. 6048, pp. 1427-1430, Aug. 2011.

[18] A. Ferretti, C. Prati, and F. Rocca, "Nonlinear subsidence rate estimation using permanent scatterers in differential SAR interferometry," IEEE Trans. Geosci. Remote Sens., vol. 38, no. 5, pp. 2202-2212, Sep. 2000.

[19] P. Berardino, G. Fornaro, R. Lanari, and E. Sansosti, "A new algorithm for surface deformation monitoring based on small baseline differential SAR interferograms," IEEE Trans. Geosci. Remote Sens., vol. 40, no. 11, pp. 2375-2383, Nov. 2002.

[20] J. Biggs, T. Wright, Z. Lu, and B. Parsons, "Multi-interferogram method for measuring interseismic deformation: Denali Fault, Alaska," Geophys. J. Int., vol. 170, no. 3, pp. 1165-1179, Sep. 2007.

[21] H. Liu, K. Jezek, and B. Li, "Development of an Antarctic digital elevation model by integrating cartographic and remotely sensed data: A geographic information system based approach," J. Geophys. Res., vol. 104, no. B10, pp. 23199-23213, Oct. 1999.
[22] R. F. Hanssen, Radar Interferometry: Data Interpretation and Error Analysis. Norwell, MA, USA: Kluwer, 2001.

[23] H. Fujisada, G. Bailey, G. Kelly, S. Hara, and M. Abrams, "ASTER DEM performance," IEEE Trans. Geosci. Remote Sens., vol. 43, no. 12, pp. 2707-2714, Dec. 2005

[24] J. L. Bamber, J. L. Gomez-Dans, and J. A. Griggs, "A new 1 km digital elevation model of the Antarctic derived from combined satellite radar and laser data-Part 1: Data and methods," The Cryosphere, vol. 3, pp. 101$111,2009$.

[25] R. Michel and E. Rignot, "Flow of Glacier Moreno, Argentina, from repeat-pass shuttle imaging radar images: Comparison of the phase correlation method with radar interferometry," J. Glaciol., vol. 45, no. 149 , pp. 93-100, 1999.

[26] H. Liu, Z. Zhao, and K. C. Jezek, "Synergistic fusion of interferometric and speckle-tracking methods for deriving surface velocity from interferometric SAR data," IEEE Geosci. Remote Sens. Lett., vol. 4, no. 1, pp. 102 106, Jan. 2007

[27] H. Liu, Z. Zhao, J. Yu, and K. Jezek, "Simultaneous least squares adjustment of multiframe velocities derived from interferometric and speckletracking methods," IEEE Geosci. Remote Sens. Lett., vol. 5, no. 2, pp. 289-293, Apr. 2008.

[28] M. Otten and J. Dow, "ENVISAT precise orbit determination," presented at the ENVISAT ERS Symp., Salzburg, Austria, Sep. 2004, H. Lacoste, L. Ouwehand, eds.

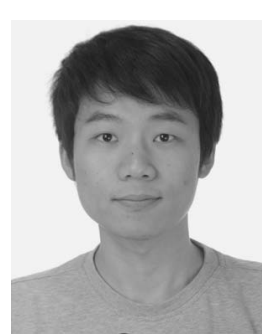

Yu Zhou received the B.S. and M.S. degrees in sciences and techniques of geodesy from Wuhan University, Wuhan, China, in 2010 and 2012, respectively. He is currently working toward the Ph.D. degree in the Department of Earth Sciences, University of Oxford, Oxford, U.K.

His research interests include space geodesy and active tectonics.

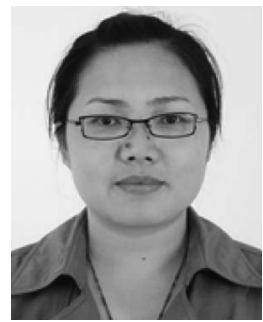

Chunxia Zhou received the B.S. and M.S. degrees in geodesy and geomatics from the Wuhan Technical University of Surveying and Mapping, Wuhan, China, in 1998 and 2000, respectively, and the Ph.D. degree in solid earth geophysics from Wuhan University, Wuhan, China, in 2005

She is currently an Associate Professor with the Chinese Antarctic Center of Surveying and Mapping, Wuhan University. She works on SAR interferometry and its application in glaciology. She has participated in fieldwork in Antarctica and Svalbard.

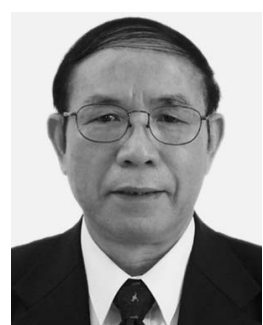

Dongchen $\mathbf{E}$ received the B.S degree in geodesy from the Wuhan Surveying and Cartographying College, Wuhan, China in 1965.

He is a Professor with Wuhan University, Wuhan, China. From 1986 to 2011, he was the Director of the Chinese Antarctic Center of Surveying and Mapping, Wuhan University. Since 1984, he has been to Antarctica seven times and the Arctic four times. His research interests include geodesy and glaciology in polar regions.

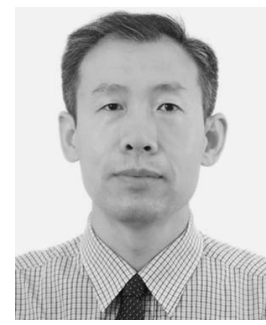

Zemin Wang received the B.S. and M.S. degrees in geodesy from the Wuhan Technical University of Surveying and Mapping, Wuhan, China, in 1985 and 1991, respectively, and the Ph.D. degree in geodesy from Wuhan University, Wuhan, China, in 2001.

From 1999 to 2005, he was a Professor with the School of Geodesy and Geomatics, Wuhan University. Since 2005, he has been a Professor with the Chinese Antarctic Center of Surveying and Mapping, Wuhan University. He is interested in geodynamics and glaciology using GPS and geodetic measurements. He has participated in fieldwork in Antarctica and Svalbard. 